\title{
Optimization and Deployment of Femtocell: Operator's Perspectives
}

\author{
Javed Iqbal $^{1, \dagger}$, Zuhaibuddin Bhutto ${ }^{2, \dagger \dagger}$, Zahid latif ${ }^{3, \dagger}$, M. Zahid Tunio ${ }^{4, \dagger \dagger}$, Ramesh Kumar ${ }^{5,+\dagger \dagger}$, Murtaza Hussain \\ Shaikh $^{6, \dagger \dagger \dagger}$, Muhammad Nawaz, ${ }^{7, \dagger}$ \\ ${ }^{\dagger}$ Department of Data Communications, National Telecommunications Corporation Islamabad, Pakistan. \\ ${ }^{\dagger}$ Department of Computer Systems Engineering, Balochistan University of Engineering \& Technology, Khuzdar, Pakistan. \\ ${ }^{\dagger \dagger}$ Dawood University of Engineering and Technology, Karachi, Pakistan. \\ ${ }^{\dagger \dagger}$ Department of Information Systems, Kyungsung University, Busan, South Korea.
}

\begin{abstract}
This study examines the deployment issues of Femtocell, which require the satisfaction level of users on available bandwidth. Femtocells are small Base Stations installed in Homes for the improvement of coverage and capacity of Cellular Networks. Femtocells are connected over traditional DSL, FTTH (fiber to the home) to the Network. Optimization of Cellular Network is required for efficient utilization of available bandwidth and resources. In this paper, we present deployments issues, optimizations of Femtocell, Operator perspective survey results, and Service level agreement (SLA) between cellular operators, which achieve the user's desires and support in the deployment of Femtocell Network.
\end{abstract}

Keywords-Femtocell; deployment; optimization; service level agreement; fixed mobile convergence; cellular networks

\section{INTRODUCTION}

Cellular networks are growing whenever users' requirements increase. and expend their Network coverage and capacity, the operator required properly optimized network and installed new base stations at less and dark coverage areas of the city. In GSM Network expansions are made through cell splitting and frequency reuse. Excess of frequency reuse can be limited due to co-channel and cross channel interference, particularly in congested areas. Expansions in cellular networks, frequency re-use and capacity enhancements in populated areas keeping in mind the cost constraints are serious problems. It is noticed that the radio signals are degraded in the interior of the buildings. The signals of $2 \mathrm{G} \mathrm{Hz}$ and above become weak when entering to individual Home/building walls. There is a large number of users inside the buildings that required network coverage. To improve network coverage, it is not convenient for the operator to install new Macrocell (BTS) due to the high cost of equipment and land requisition especially in congested urban areas however this approach has some drawbacks.

New technologies are being looked by operators for coverage and better services inside the buildings. The new technology called Femtocell is proposed for enhancing network capacities and coverage. Femtocells are small base stations that operate in the licensed cellular bands. They are small, inexpensive, and transmit at low power and are to be placed in individual homes and backhauled onto the operator's network via conventional Digital Subscriber Lines (DSL).
Macrocell covers a large area having a large number of users can be accommodated. Together with the concept coverage and the economics of femtocells characterize a radical arrival from traditional macro radio access networks. Femtocell arrangement inside the home and ability to be customized to the needs of individual consumers promise to rapidly will make them major components of the operators' business. Femtocells have achieved a lot of attention due to the benefits offered in terms of cellular infrastructure cost saving, load balancing, and indoors improved user requirements [1]. Femtocells ideas were presented in 1999 however it starts vide spread markets attractions in 2007 [2]. Cellular operators are especially interested in Femtocells commercial deployment for increasing capacity and improve coverage.

The main contributions of this study can be summarized as follows:

- From user's perspective this study a novel approach of femtocells deployment in an individual home, which are very attractive due to the dedicated line of backhauled network and improved coverage.

- Generally in Universal Telecommunications System (UMTS) networks an indoor user will require higher power drain from the base station in order to overcome high penetration loss. This will result in less power to be used by other users and lead to reduced cell throughput. This study put forward important recommendations to overcome the power consumption.

\section{Possible Scenarios of THE Femtocell}

Cellular networks are evolutionary on the rise. Initially, AMPS analog wireless communications were developed only for voice. The development of new technologies makes it possible to formulate digital communication from AMPS $1 \mathrm{G}$ toward 2G GSM.

\section{A. GSM Femtocell Architecture}

GSM was designed for voice communication with relatively high capacity and reliability. The GSM operates in $900 \mathrm{MHz}, 1800 \mathrm{MHz}$ bands. The frequencies of these types have a characteristic to travel up to $40 \mathrm{~km}$. GSM has a data rate of one TDM slot $9.6 \mathrm{~kb} / \mathrm{s}$ to $14 \mathrm{~kb} / \mathrm{s}$. the data requirements come in and need data in mobility. The data rates of traditional 
GSM were slow. The engineers create different techniques to enhance modulation and usage of multiple time slots for single users.

These modifications lead the GSM systems towards the GPRS/EDGE GSM 2.7G. The enhance Modulations such as Orthogonal phase shift keying (8 PSK) which can achieve a data rate up to $48 \mathrm{~kb} / \mathrm{s}$ per carrier slot. Thus, this technique can enhance the data rate to $8 \times 48=384 \mathrm{kbps}$. GSM signals are easily entered in customer's premises and penetrate. Generally, it is observed that in GSM networks femtocell not required however in some places Pico-cell are used, however, the cost of Pico-cell is 50time more than femtocell and femtocell installation will defiantly decrease the operator's capital expenditures. The other reason that GSM has no efficient power control mechanism as compared to UMTS which may cause interference with Macrocell (as shown in Fig. 1).

\section{B. Femtocell Architecture}

In a UMTS network for femtocell deployment, different scenarios have been proposed. The newest advancement allows powerful processing means which are used in low-cost home base stations. The network protocols are now changing and new protocols have been introduced. Internet Protocol (IP) is now replacing particular transmission protocols. Flat networks architecture is experienced in femtocell deployment, which using collapsed protocol stacks and internet protocol. Internet protocol is used for backhaul transport to operator networks. For deployment of femtocell different network architectures have been proposed. Initially, flat architecture was introduced in which the Security-Gateway (SG) is placed between the Mobile operator network and femtocell Home Node-B. Home Node-B is the technical name of femtocell [6].

The newest architecture for Femtocell interfacing to cellular operator network is generally referred to as Radio Access Network (RAN) Gateway solutions [3] [4]. The RAN gateway is placed between the IP network and operator network controller (RAN Gateway) that resides between an operator's existing core networks. These RAN gateways incorporate large traffic from large numbers of Femtocell on Iu over IP the interface introduced for femtocell access to UMTS network [3]. The RAN gateway incorporates this large traffic of femtocell to operator network on $I u$-PS (Iu-packet switch, interface defined for RAN gateway and SGSN of UMTS network) and $I u$-CS (Iu circuit switch, the interface between RAN gateway and MSC of the network) [5]. The RAN getaway uncomplicated femtocell deployment for operators to deploy mass deployment of the femtocell with lowest expenditures. In this architecture, the standard functionality of RNC (Radio network controller) is included in the femtocell. Femtocell (Home NodeB) is now more intelligent and is called 'Femto Access Point' by the advancement of access technologies and hunger for More data access in mobility 3GPP introduces LTE long term Evolution access technology which can guarantee up to 50Mbps [7]. Femtocells implementations have few issues and challenges, which need to be addressed properly before mass deployment.

\section{LTE Femtocell Architecture}

LTE long term evolution is introduced in 3GPP release 8. Initially, it was designed for $3 \mathrm{G}$ however the newer version of have been introduced in 3GPP onward releases. LTE based on MIMO multiple inputs and multiple outputs. LTE use OFDMA technology on the air interface, which improves its capacity of $100 \mathrm{mbps}$ in downlink and 50kbps in the uplink [8]. In this, as the data rate has been increased using cellular networks, so this is called the "data explosion" technology. In LTE OFDMA is used for downlink and SC-OFDMA single carrier OFDMA for uplink to avoid inter users' interferences.

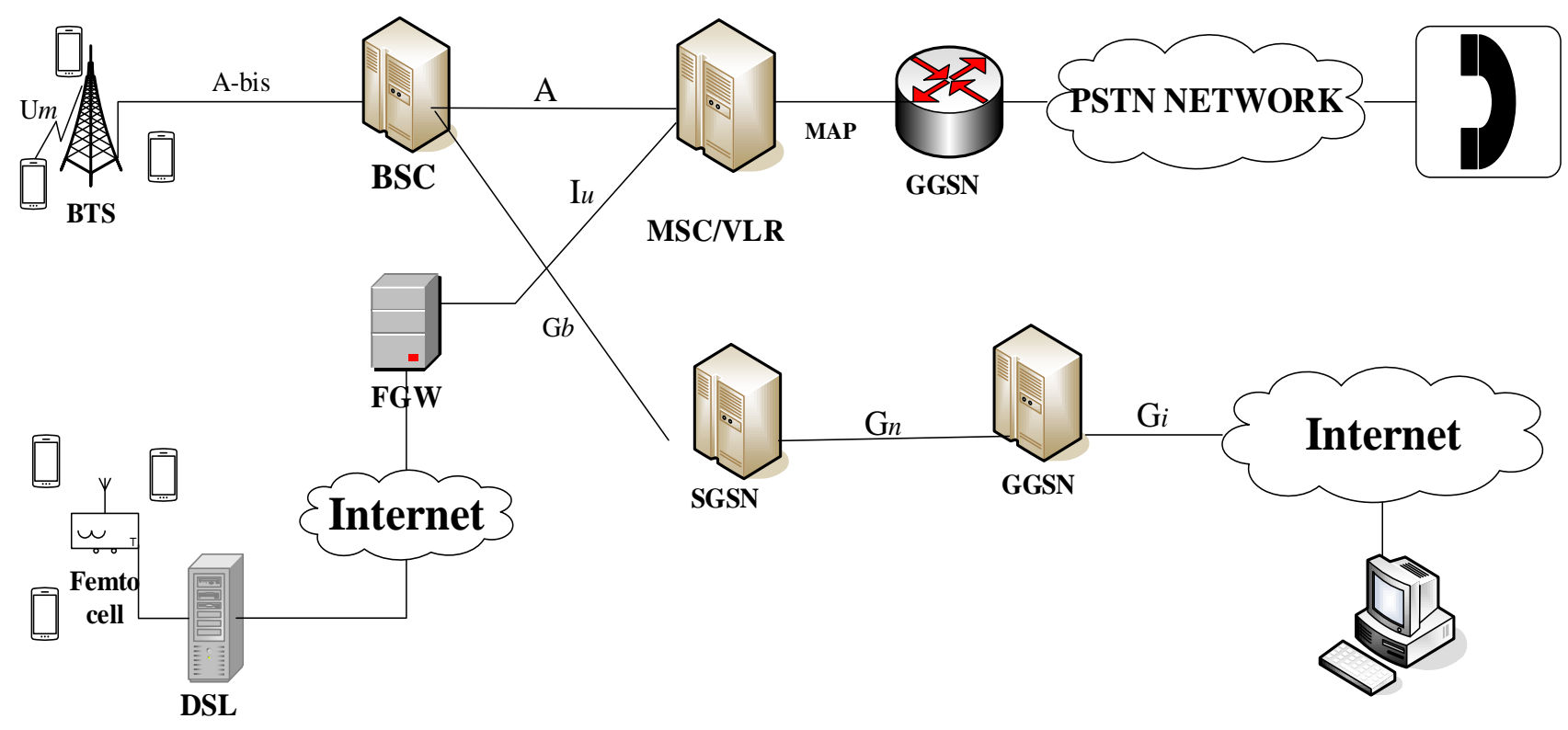

Fig 1. GSM Femtocell Architecture. 


\section{Femtocell Issues ANd Challenges}

\section{A. Interference Challenges of Femtocell}

1) Interference is experienced when a user equipment (UE) moves in the coverage area of Femtocell and the user is not registered to Femtocell. On the other side when Femtocell is working in the coverage of Macrocell it will also interfere in macro cell and Femtocell coverage. It is considered that these networks are two separate layers the Femtocell and macro cell layers. Cross-Layer interference refers to situations in which the attacker FAP, Femtocells access point and the sufferer Macrocell user of interference belong to different network layers. In Co-Layer interference the aggressor FAP and the victim, neighboring Femtocell users belong to the same network layer. One preferred technique has been proposed to use a separate frequency range for Femtocell and microcell however this technique can change the operator's motivation and thinking for Femtocell deployments to use such an expensive solution of frequency bands. To overcome the effects of interference, cancellation techniques have been proposed but often disregarded due to errors in the cancellation process [15] [16].

\section{B. Femtocell Access Procedures}

In this type of scenario, the operator uses the Femtocell in shadow coverage and in commercial places where macro cell coverage not exist. In this type of access technique, all users are allowed to connect with the femtocell. The users in which are inside the home and building and the guest users that are outside the building in femtocell access can use the Femtocell services.

\section{Femtocell Closed Access Procedure}

When the Femtocell was installed in the individual home is not willing to allow others to use their back-end services. The Femtocells only allow subscribed and registered users to establish connections. The outsider non-registered and guest users will be disallowed to use the femtocell services.

\section{Femtocell Hybrid Access Procedure}

Non-subscribers (not-registered) use only limited Femtocells resources. The outsiders and guest users can only use femtocell services in emergency services.

\section{E. Femtocell Synchronization with the Macrocell}

Femtocell equipment is proposed to be cheap which can easily be installed in every home. Inexpensive Femtocells with high precision oscillators is not possible. to minimize multiaccess interference time synchronization is necessary between macro cells and Femtocells, as well as for the proper performance of handoffs and could lead to the uplink period of some cells overlapping with the downlink of others, thus increasing inter-cell interference in the network. There are proposed solutions for Femtocells time synchronizations, GPS and IEEE1588 precession protocols are feasible solutions. In GPS time synchronization can affect network performance because GPS coverage is available in some places so the other IEEE1588 precession protocol can be used for Femtocell time synchronization.

\section{F. Physical Cell Identity for Femtocell}

Physical cell identity (PCI) is used to identify a cell for radio intention like camping and handoff events are simplified by explicitly providing the list of PCIs that mobile terminals have to monitor. The PCI of a cell does not need to be unique across the entire network; however, it must be unique on a local scale to avoid confusion with neighboring cells.

\section{G. Femtocell users Mobility Management}

In cellular networks, handoffs take place when users enter in the coverage area of other cells. For open and hybrid access Femtocells, handoffs occur more often than in the macro cell case and increasing network signaling. Different handoff management procedures are thus needed to allow nonsubscribers to camp for longer periods on nearby Femtocells.

Cellular networks are trying to reduce its capital expenditures and operating cost. The femtocell deployment is the main issue. The users who install DSL in his home are not willing to use their backend services to other users which came in during mobility from another Macro or Femtocell. The deployment of the femtocell is the main issue. There are some positions, which need to be clarified before mass deployment of Femtocells in rural and urban areas [17] [18].

\section{OPERAtors Perspective SURVEY}

An operator's perspective survey conducted in Pakistan from different operators in different cities Karachi, Lahore, Islamabad, Rawalpindi, Quetta, Bannu, Peshawar, Mardan, and Nowshera. Operators are looking for network expansion. PTCL is the large landline operator in Pakistan is facing problems in network expansion in urban areas, particularly in congested city areas. The development agencies are not permitting for a new expansion of the landline (copper) network. Now PTCL is moving toward wireless solutions and acquire the CDMA 2000 license from Pakistan Telecomm authority. All other GSM operators are also looking for more network expansion and facing co-channel and adjacent channel interference problems when installing new BTS's in congested areas. These high-populated networks need accurate optimizations.

In this section, questions from the survey are categorized into different sections. Each section has the relevant questions tabulated, the table representing the results of the corresponding questions and finally the graph giving an insight of the conducted survey.

\section{A. Existing Installed DSL and Payments}

Four questions asked in this category as listed in Table 1. These questions were asked from 40 different operators' representatives. Mostly the questions were asked about the installed DSL connection and payments modes. In Table 2, the results of the survey are tabulated and based on the results (answers), percentage plots are made as shown in Fig. 2. In 1 st Question above 58\% of operators and vendors have agreed on that users will pay extra for femtocell device and $42 \%$ of operators replied that users will not pay more by installing femtocell in their homes and asked in Q2, 73\% of operators are agreed to provide free of cost femtocell device for best network coverage and business expansions. 
TABLE I. EXISTING INSTALLED DSL AND PAYMENTS RELATED QUESTIONS

\begin{tabular}{|l|l|l|}
\hline Q. No & Question & $\begin{array}{l}\text { Answer } \\
\text { Choices }\end{array}$ \\
\hline 1 & $\begin{array}{l}\text { Considering the fact that consumers already } \\
\text { having access to the internet via high-speed } \\
\text { ADSL connection usually have to pay for a } \\
\text { wireless router that is provided by their service } \\
\text { provider. Do you think they would opt to pay } \\
\text { extra for a femtocell base station? } \\
\text { If No, then answer Q2. }\end{array}$ & $\begin{array}{l}\text { i. Yes } \\
\text { ii. No }\end{array}$ \\
\hline 2 & $\begin{array}{l}\text { Would you consider providing them the femtocell } \\
\text { base stations free of charge? }\end{array}$ & $\begin{array}{l}\text { i. Yes } \\
\text { ii. No }\end{array}$ \\
\hline 3 & $\begin{array}{l}\text { Those consumers who already pay a fee for their } \\
\text { ADSL connection would find it viable to pay } \\
\text { extra for the data services using the femtocell } \\
\text { base station only because it can provide a } \\
\text { relatively higher data rate when compared to } \\
\text { usual indoor access without a femtocell base } \\
\text { station. }\end{array}$ & $\begin{array}{l}\text { i. Yes } \\
\text { ii. No }\end{array}$ \\
\hline 4 & $\begin{array}{l}\text { Would you consider providing them with cost- } \\
\text { effective data access plans? }\end{array}$ & $\begin{array}{l}\text { i. Yes } \\
\text { ii. No }\end{array}$ \\
\hline
\end{tabular}

TABLE II. RESULTS OF THE EXISTING INSTALLED DSL AND PAYMENTS RELATED QUESTIONS

\begin{tabular}{|l|l|l|l|}
\hline \multirow{2}{*}{ S. No. } & \multirow{2}{*}{ Question No. } & \multicolumn{2}{|c|}{ Answer Percentage } \\
\cline { 3 - 4 } & & Choice (i) & Choice (ii) \\
\hline 1 & 1 & $58 \%$ & $42 \%$ \\
\hline 2 & 2 & $73 \%$ & $27 \%$ \\
\hline 3 & 3 & $56 \%$ & $44 \%$ \\
\hline 4 & 4 & $75 \%$ & $25 \%$ \\
\hline
\end{tabular}

In Pakistan some cities particularly, hilly areas where people would like to talk through the cellular network and there is no DSL service available, the operators were asked in Q7 regarding Multi-Hop coverage by deploying Femtocell. $72 \%$ operators are willing to deploy Femtocell in such a manner that make an ad-hoc network and rely on the data through Femtocells toward macro-cell. This solution is looking very viable in rural areas and villages where no DSL connection available which will ultimately reduce the cost of DSL services.

Operators were asked in Q3, 44\% of the operators and vendors have replied that the users will not pay extra for data services using femtocell base station inside their homes. 56\% responded that according to the demands of customers they will pay for more for better services and coverage with mobility. 75\% of Operators repetitive suggested in Q4 that cost-effective data solutions would be provided to value-added customers.

\section{B. Skype usage and Multihop Coverage for Femtocell}

In this section, we asked operators about the Skype users who using VOIP call in free of cost and deployment of femtocells in those areas where DSL services are not available. These questions were asked from 40 different operators' representatives as listed in Table 3. In Table 4, we summarized the questions that were asked during the survey and the results are shown in Fig. 3.

\section{Existing installed DSL and payments}

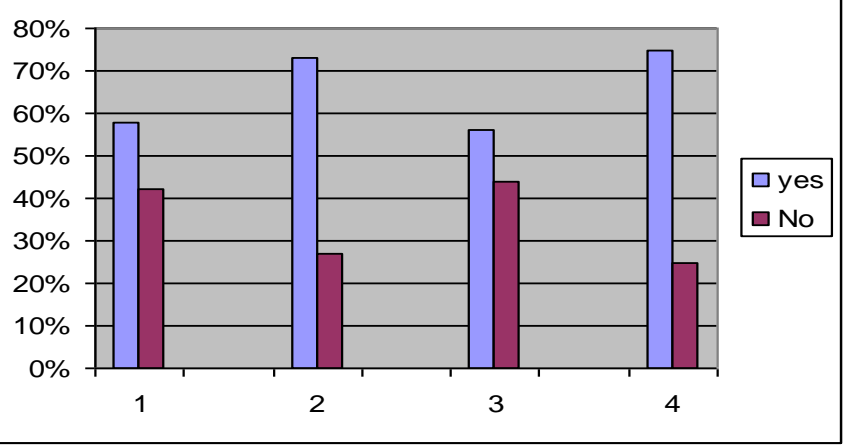

Fig 2. Existing Installed DSL and Payments.

TABLE III. SKYPE UsAgES AND Multi-Hop COVERAGE OF FEMTOCELL

\begin{tabular}{|l|l|l|}
\hline Q. No & Question & $\begin{array}{l}\text { Answer } \\
\text { Choices }\end{array}$ \\
\hline 5 & $\begin{array}{l}\text { With the increase in the user support for Voice } \\
\text { over IP solutions like Skype due to the exponential } \\
\text { rise in the broadband consumer base, don't you } \\
\text { think that customers would prefer to make a } \\
\text { majority of calls using the WLAN interface in } \\
\text { their smartphones using Skype that is free of cost } \\
\text { to another Skype user? Also, in UK companies } \\
\text { like 3G are providing Skype phones without any } \\
\text { data usage charges for Skype and hence the users } \\
\text { can make a majority of their calls from Skype to } \\
\text { Skype free of charge? }\end{array}$ & i. Yes \\
ii. No \\
\hline 6 & $\begin{array}{l}\text { Do you have any attractive alternatives to still } \\
\text { drive the users towards paying for the femtocell } \\
\text { base station and data services using the femtocell? }\end{array}$ & $\begin{array}{l}\text { i. Yes } \\
\text { ii. No }\end{array}$ \\
\hline 7 & $\begin{array}{l}\text { Would you consider deploying femtocell where } \\
\text { DSL connectivity is not available, and users relay } \\
\text { voice and data services to the macrocell base } \\
\text { station through a multi-hop path via femtocell } \\
\text { coverage sharing? }\end{array}$ & $\begin{array}{l}\text { i. Yes } \\
\text { ii. No }\end{array}$ \\
\hline
\end{tabular}

TABLE IV. RESUlts OF THE SKyPE USAGES AND Multi-HOP COVERAGE OF FEMTOCELL RELATED QUESTIONS

\begin{tabular}{|l|l|l|l|}
\hline \multirow{2}{*}{ S. No. } & \multirow{2}{*}{ Question No. } & \multicolumn{2}{|l|}{ Answer Percentage } \\
\cline { 3 - 4 } & & Choice (i) & Choice (ii) \\
\hline 1 & 5 & $81 \%$ & $19 \%$ \\
\hline 2 & 6 & $61 \%$ & $39 \%$ \\
\hline 3 & 7 & $72 \%$ & $28 \%$ \\
\hline 4 & 4 & $75 \%$ & $25 \%$ \\
\hline
\end{tabular}




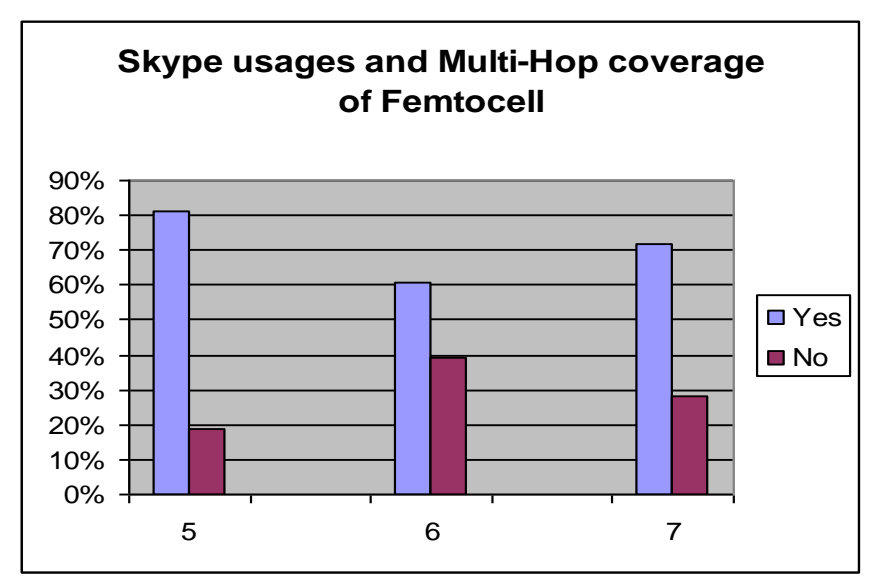

Fig 3. Skype usage and multi-hop coverage of Femtocell.

Telecom operator's representative was asked in Q5 about the Skype, free of cost VOIP calls and takes the feedback from operators that they would like to offer free calls.

The operators showed $81 \%$ interest in this type of services. This service will enhance network coverage and network capacity. All users have no Skype phones from calling party to called party; either of the users may use different operator's services. In this type of situation, the Cellular network calls are needed and defiantly the users will use the cellular network for calls. In Pakistan, the market environment is not so much change that mostly the users will use Skype services. Operator's representatives were asked in Q6 about femtocell deployment still in existing with Skype services. 61\% replied that there are some alternatives that will change the users' attractions for paying femtocell base stations. Users desire for Network coverage with mobility inside the buildings.

In Pakistan some cities particularly, hilly areas where people would like to talk through the cellular network and there is no DSL service available, the operators were asked in Q7 regarding Multi-Hop coverage by deploying Femtocell. $72 \%$ operators are willing to deploy femtocell in such a manner that make an ad-hoc network and rely on the data through femtocells toward macro-cell. This solution is looking very viable in rural areas and villages where no DSL connection available which will ultimately reduce the cost of DSL services.

\section{Femtocell DePloyment ReQuirements For SLA}

In a situation where the femtocell efficiency may be degraded in case of any congestion in the IP network. The solution for this dilemma to acquire enhance DSL bandwidth from service providers. It is important that the advancement of Telecom networks infrastructure in Pakistan the operators are now able to provide DSL, LAN and WAN connections up to $40 \mathrm{Mb} / \mathrm{s}$ and $1.25 \mathrm{~Gb} / \mathrm{s}$ can be provided on GPON networks. At this situation, the users will difinetly compare the cost of the service which may manipulate the femtocell deployment [9].

Mobile operator and DSL services provider has to service level agreement for providing at least $500 \mathrm{~kb} / \mathrm{s}$ bandwidth for the users of femtocell traffic [10]. The users of real-time traffic need dedicated bandwidth of sufficient amount. If the required bandwidth not allocated to real-time traffics then the packets of voice and video can be discarded and dropped due to congestion in a broadband network. The Broadband operators mostly deploy the DSL CPE (customer premises equipment) remote WAN management protocol TR 069 [11]. This type of protocol is enabling the operators to manage the DSL modem remotely.

The real-time traffic uses UDP in which small packets are forwarded in the network with the hope of timely reach to it destinations however these packets have no guarantee to reach its intended receivers. The DSL operators may use the QOS protocol TR 098 [12] to enable remote management configurations that will prioritize the real-time packets including Voice packet VOIP, IPTV and other real traffics. The QOS solution based on SLA service level agreement along with DiffServ which give priorities to small packets and deliver these packets to its receivers [13] [14]. If femtocell users using the required Bandwidth and another user want to establish the calls then call will not be established or the other users will the victim of call drop. The operator will establish the QoS based algorithms that will enhance and modify the Satisfaction level calls. In a situation, if the users are increased and want to establish the voice and video calls then the bandwidth of the existing call to be decreased and not drop the calls. An SLA between mobile operators of FAP and DSL providers will ensure bandwidth reservations for Femto user's calls.

\section{CONCLUSION}

Deployment of Femtocell in Pakistan will be recognized in near future. The DSL connection should be properly optimized to a certain level and values before deploying femtocell. Service level agreement SLA between the DSL service provider and cellular network operator will ensure the maximum connectivity of femtocell users to the cellular core network. The femtocell deployments will improve network coverage and enhance capacity. The operators are spirited for Femtocell mass deployment. Users wanted to exercise multimedia services and other social networks through wireless communication. The operators in Pakistan are hopeful for their coverage and capacity enhancing in black hole areas after mass deployment of Femtocells.

\section{REFERENCES}

[1] L. Menshawy, H. Nashaat, R. Rizk, "Multi-Objective Handoff Scheme for Macro/Femto WiMAX Networks". Journal of Circuits, Systems, and Computers, Vol. 28, No. 01, 2019.

[2] N. Kayastha, D. Niyato, "A Review of Radio Resource Management in FemtoCell from Interference Control Perspective," Transactions on Computer and Information Technology Vol. 11, No. 2, pp. 103-128, 2017.

[3] TS 43.318, Generic Access Network (GAN) Stage 2, Rel-5

[4] 3GPP TS 44.318, Generic Access Network (GAN); Mobile GAN Interface Layer 3 Specification, Rel-5.

[5] 3GPP TS 25.434 UTRAN Iub Interface Data Transport and Transport Signaling for Common Transport Channel Data Streams, Rel-7

[6] M. Al-omari, A. R. Ramli, A. Sali, R. S. Azmir, "A femtocell cross-tier interference mitigation technique in OFDMA-LTE system A Cuckoo search based approach," Indian Journal of Science and Technology, Vol. 9, No. 2, 2016. 
[7] H. Claussen, T. W. H. Lester, G. S. Louis, "Self-optimization of coverage for femtocell deployments," Wireless Telecommunications Symposium, pp. 278 - 285, Pomona, CA, USA, April 2008.

[8] S. S. Prasad, R. Baruah, "Femtocell mass deployment: indian perspective," 3rd International Conference on Anti-counterfeiting, Security, and Identification in Communication Hong Kong, China, October 2009

[9] C. Yang, J. Xiao, J. Li, X. Shao, A. Anpalagan, Q. Ni, M. Guizani, "Interference-Aware Distributed Cooperation with Incentive Mechanism for 5G Heterogeneous Ultra-Dense-Networks," IEEECommunications Magazine, Vol. 56, No. 7, pp.198-204, March 2018.

[10] M. Z. Chowdhury, S. Coi, Y. M. Jang, "Dynamic SLA negotiation using bandwidth broker for femtocell networks" International Conference on Ubiquitous and Future Networks (ICUFN), Hong Kong, pp 12-15 June 2009.

[11] TR-069 (Technical Report 069) is a DSL Forum, CPE WAN management protocol, an application layer protocol for remote management of end-user.

[12] TR-068 (Technical Report 068) is a DSL Forum, Internet access via ADSL or SHDSL over QoS-enabled ATM architecture. Supports VoIP. TR-068 : Base Requirements for an ADSL Modem with Routing.
[13] V. Ward, S. Smith, J. Keen, R. West, A. House, A, "Creating and implementing local health and wellbeing policy: networks, interactions and collective knowledge creation amongst public sector managers. Evidence \& Policy," A Journal of Research, Debate and Practice, Vol. 14, No. 3, pp. 477-498, August 2018.

[14] A. J. Gonzalez, M. Xie, P. Grønsund, "Network Slicing Architecture and Dependability," International Conference on Mobile, Secure, and Programmable Networking, pp. 207-223, Springer, Cham.

[15] Z. Latif, W. Lei, S. Latif, Z. H. Pathan, R. Ullah, R., Z. Jianqiu, "Big data challenges: Prioritizing by decision-making process using Analytic Network Process technique," Multimedia Tools and Applications, 1-27, 2017.

[16] G. Capuozzo, O. Onorato, A. Imparato, D. D'errico, G. D'angelo, U.S. Patent Application No. 15/204,344, 2018.

[17] Z. Latif, M. Z. Tunio, Z. H. Pathan, Z. Jianqiu, L. Ximei, S. K. Sadozai, "A review of policies concerning development of big data industry in Pakistan: Subtitle: Development of big data industry in Pakistan," IEEE nternational conference on computing, mathematics and engineering technologies (iCoMET), pp. 1-5, March 2018.

[18] S. M. A. El-atty, Z. M. Gharsseldien, K. A. Lizos, "Predictive Reservation for Handover Optimization in Two-Tier Heterogeneous Cellular Networks. Wireless Personal Communications," Vol. 98, No. 2, pp. 1637-1661, January 2018. 